\title{
Power Quality and Digital Protection Relays
}

\author{
I. Zamora ${ }^{1}$, A.J. Mazón ${ }^{2}$, V. Valverde, E. Torres, A. Dyśko ${ }^{(*)}$ \\ Department of Electrical Engineering - University of the Basque Country \\ Alda. Urquijo s/n, 48013 Bilbao (Spain) \\ Phone:+34 946014063 , fax:+34 946014200 , e-mail: ${ }^{1}$ iepzabei@bi.ehu.es ${ }^{2}$ iepmasaj@bi.ehu.es
}

(*) Department of Electronic and Electrical Engineering - University of Strathclyde 204 George Street, Glasgow (United Kingdom)

\begin{abstract}
Power Utilities need to satisfy the demands of supplying high quality of power to their consumers efficiently and effectively, while maintaining investments and generating profit. The use of digital multifunction relays and their proper integration into power system is an important element of this process. However, the performance of digital relays depends on many factors and needs to be carefully evaluated. In the first part of the paper the main advantages and limitations related to digital relays are outlined. The key standards related to power quality are introduced and their relevance to protective relaying is indicated. Finally, the influence of power quality on protection relays is assessed through several simulation examples using the software tool Mathcad.
\end{abstract}

Key words. Power Quality, Reliability, Digital relays.

\section{Introduction}

Today's advanced industrial processes are often sensitive to power supply interruptions and voltage distortions. On the other hand, the growing use of non-linear loads generates interference and contributes to the increased levels of voltage contamination in power networks. This situation can impact normal operation of other customers connected to those networks. Thus, in recent years the sensitivity towards power quality issues has been increasing mainly as a result of the demands posed by many consumers.

Power quality can be defined by four fundamental parameters: frequency, amplitude, shape and symmetry. It is quantified by evaluating these parameters and comparing them with the normative limits. Depending on which of these parameters fall outside the prescribed limits, there will be different phenomena affecting power quality supplied to customers. The main characteristics of these phenomena are:

- Frequency variation results from the small changes in the dynamic balance between load and generation levels. The amount of frequency shift and its duration depends on the load characteristics and response of the generation control system to load changes. When load is higher than generation, frequency decreases, whereas, when the load is lower than generation, frequency increases. The power system frequency is directly related to the rotational speed of the generators supplying the system.

- Amplitude. The typical phenomena related to wave amplitude, and its main characteristics are defined in table I.

TABLE I - Phenomena related to amplitude

\begin{tabular}{|c|c|c|}
\hline & Duration & Magnitude \\
\hline Voltage fluctuation & $>10 \mathrm{sg}$ & \\
\hline Fast voltage fluctuation & $\mathrm{ms}-10 \mathrm{sg}$ & $<10 \% \mathrm{Un}$ \\
\hline Voltage sag & $10 \mathrm{~ms}-\mathrm{sg}$ & $90 \% \mathrm{Un}$ \\
\hline Short interruption & $10 \mathrm{~ms}-1 \mathrm{~min}$ & $100 \% \mathrm{Un}$ \\
\hline Voltage pulse & $\mu \mathrm{s}-10 \mathrm{~ms}$ & From 1 to $5 \mathrm{Un}$ \\
\hline
\end{tabular}

- Shape. Harmonic distortion is the phenomena related to the wave shape. Non-linear loads introduce components with frequencies that are multiples of the fundamental system frequency. These higher frequency components are called harmonics. The change of wave caused by these harmonics is called harmonic distortion. In most practical applications, harmonic amplitudes decrease with harmonic order, being the third-order harmonic the most important.

- Symmetry. In a three phase system when the RMS values are not equal or phase angles are not symmetrically shifted by $120 \mathrm{deg}$, a voltage imbalance is present in the system. It is usually caused by singlephase loads.

The voltage waveform produced by the generators is relatively clean and the above four parameters are close to the normative values. However, wave quality is affected by the presence of a wide range of disturbances throughout the transmission and distribution network. One of the most important factors causing these disturbances is the connection of non-linear and singlephase loads by the customers. Moreover, sometimes power quality can be affected by other transient phenomena such as system fault events, switching or meteorological conditions. The complete elimination of these events is impossible, therefore, it is necessary to 
implement various measures in order to minimize the negative effects on customers. Depending on which of the power quality parameters is distorted the influence on the performance of digital protection relays will be different.

\section{Protective Relays}

Protection relay is a device which by means of measuring power system quantities (currents and voltages) and processing them through its internal logic, has the capacity to control the operation of a circuit breaker. The internal logic allows the relay to initiate a tripping sequence when anomalous conditions arise within the power system.

With regard to their construction three types of relays can be distinguished: electromechanical, static and digital. In electromechanical relays, the actuating force is created by electromagnetic interaction. Static relays are based on analogue electronic components such as diodes, transistors, capacitors, etc. whereas numerical relays have their logic implemented in software and microprocessor technology. Some relay designs combine the static and digital technology. This paper concentrates on the analysis of digital relays.

\section{A. Digital Relays}

A digital relay consists of the following main parts: processor, analogue input system, digital output system and independent power supply [1]. Figure 1 presents a simplified block diagram of a digital relay.

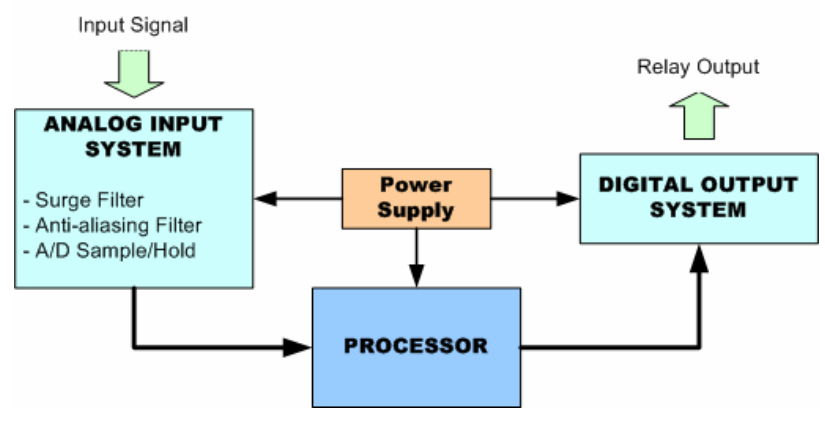

Fig. 1. Block diagram of a digital relay

The main difference between digital and conventional relays pertains to the method of input signal processing. In the case of digital relays, input signals are converted into digital form within the analogue input system before being analysed by the processor.

Digital relays possess advanced programmable functionality providing high performance level, flexibility as well as additional monitoring capabilities. At present, their application is mainly in transmission system and generation unit protection. The main advantages and drawbacks are listed below. a) Advantages

- High level of functionality integration.

- Additional monitoring functions.

- Functional flexibility.

- Capable of working under a wide range of temperatures.

- $\quad$ They can implement more complex function and are generally more accurate

- Self-checking and self-adaptability.

- They are able to communicate with other digital equipment (pear to pear).

b) Drawbacks

- Short lifetime due to the continuous development of new technologies. The devices become obsolete rapidly.

- Susceptibility to power system transients.

- As digital systems become increasingly more complex they require specially trained staff for proper maintenance of the settings and monitoring data.

\section{B. Protection functions}

Protection relays typically consist of one or more of the following basic protective components: voltage units (i.e. undervoltage and overvoltage), overcurrent units, distance protection and differential protection.

Undervoltage, overvoltage and overcurrent units are designed to operate when the amplitude of the input signal exceeds (or falls below in case of undervoltage) a pre-set threshold. The operation can be instantaneous or time delayed.

Distance protection units derive fault impedance from the voltage and current signals and compare it with the preset threshold value in order to establish whether the fault occurred within the protected zone. This type of protection is mainly used in HV transmission lines.

Differential protection relays measure the difference between the currents at the two opposite ends of the circuit allowing the protection to determine whether the fault occurred inside or outside of the protected circuit. Due to the communication requirements between two ends of the circuits, this type of protection is more suitable for generators, transformers and short transmission lines.

\section{Standards Related to Power Quality}

\section{A. EN 50160}

The European Standard EN 50160 [2] defines the main voltage characteristics at the customer's terminals in public low voltage and medium voltage distribution systems. It was published by the European Committee for Electrotechnical Standardization (CENELEC) in 1999. The standard describes voltage characteristics concerning 
frequency, magnitude, waveform distortion and threephase symmetry.

- Frequency variations: nominal frequency must be 50 Hz. In normal operating conditions the fundamental frequency, averaged over a period of $10 \mathrm{~s}$, must remain within the limits specified in table II.

TABLE II - Limits for fundamental frequency

\begin{tabular}{|c|c|c|c|}
\hline \multicolumn{2}{|c|}{ Interconnected networks } & \multicolumn{2}{c|}{ Islanded networks } \\
\hline $\begin{array}{c}\text { During } \\
99.5 \% \text { of a } \\
\text { week }\end{array}$ & $\begin{array}{c}\text { During } \\
100 \% \text { of the } \\
\text { time }\end{array}$ & $\begin{array}{c}\text { During } \\
95 \% \text { of a } \\
\text { week }\end{array}$ & $\begin{array}{c}\text { During } \\
100 \% \text { of the } \\
\text { time }\end{array}$ \\
\hline $50 \mathrm{~Hz} \pm 1$ & $50 \mathrm{~Hz}+4 /-6 \%$ & $50 \mathrm{~Hz} \pm 2$ & $50 \mathrm{~Hz} \pm 15$ \\
\hline
\end{tabular}

- Voltage fluctuations: for every one week period, 95\% of the RMS values (measured as 10 min average) have to stay within the range of $U_{n} \pm 10 \%$. Additionally, in LV networks only all 10 min average RMS values must remain within the range of $U_{n}+10 \%-15 \%$.

- Fast voltage fluctuations (flicker) are usually caused by fast variation in load. In normal operating conditions fast variations usually do not exceed $5 \% \mathrm{U}_{\mathrm{n}}$ in $\mathrm{LV}$ networks and 4\% in MV networks. However, in certain conditions, these fluctuations can reach $10 \%$ in $\mathrm{LV}$ networks and $6 \%$ in MV networks. It is recommended that in every one week period, long term flicker severity $\left(\mathrm{P}_{\mathrm{lt}}\right)$ caused by voltage fluctuations should not exceed 1 during $95 \%$ of the time.

- Voltage sags: this phenomenon is predominantly random and its occurrence depends on the type of distribution network as well as the observation point. Typical values in normal operating conditions vary from several tens to a thousand per year. Majority of the sags have less than a second duration and depth below $60 \%$.

- Voltage imbalance: in every period of one week, $95 \%$ of the time the $10 \mathrm{~min}$ average value of the negative voltage sequence component must be between $0 \%$ and $2 \%$ of the positive sequence value. In the areas with predominantly single phase or two phase loads imbalances can reach $3 \%$.

TABLE III - RMS values of each harmonic

\begin{tabular}{|c|c|c|c|c|c|}
\hline \multicolumn{4}{|c|}{ Odd harmonics } & \multirow{2}{*}{\multicolumn{2}{|c|}{ Even harmonics }} \\
\hline \multicolumn{2}{|c|}{ Non-multiples of 3} & \multicolumn{2}{|c|}{ Multiples of 3} & & \\
\hline Order & $\begin{array}{l}\text { Individual } \\
\text { Distortion }\end{array}$ & Order & $\begin{array}{l}\text { Individual } \\
\text { Distortion }\end{array}$ & Order & $\begin{array}{l}\text { Individual } \\
\text { Distortion }\end{array}$ \\
\hline 5 & $6 \%$ & 3 & $5 \%$ & 2 & $2 \%$ \\
\hline 7 & $5 \%$ & 9 & $1,5 \%$ & 4 & $1 \%$ \\
\hline 11 & $3,5 \%$ & 15 & $0,5 \%$ & $6 \ldots 24$ & $0,5 \%$ \\
\hline 13 & $3 \%$ & 21 & $0,5 \%$ & & \\
\hline 17 & $2 \%$ & & & & \\
\hline 19 & $1,5 \%$ & & & & \\
\hline 23 & $1,5 \%$ & & & & \\
\hline 25 & $1,5 \%$ & & & & \\
\hline \multicolumn{6}{|c|}{$\begin{array}{c}\text { Values corresponding to harmonics of an order above } 25 \text {, which } \\
\text { generally are weak and very unforeseeable due to resonant } \\
\text { effects, are not indicated in this table }\end{array}$} \\
\hline
\end{tabular}

- Harmonic voltages: in every period of one week, $95 \%$ of the $10 \mathrm{~min}$ average RMS values of each voltage harmonic cannot exceed the values shown in table III.

Also, Total Harmonic Distortion (THD) cannot exceed $8 \%$.

$$
T H D=\frac{\sqrt{\sum_{2}^{h} A_{h}^{2}}}{A_{1}}
$$

There are other specific standards related to harmonics only. The most important ones are those defined by IEC 1000-4-7 and IEEE 519.

\section{B. IEC 1000-4-7}

The standard IEC 1000-4-7 [3] gives some recommendations on the methods and devices used for the measurement of harmonic distortion. This guide is applicable to instrumentation intended for measuring voltage or current components with frequencies in the range of D.C. to $2500 \mathrm{~Hz}$ which are superimposed on the voltage or current at the power supply frequency. This guide distinguishes frequency-domain and time-domain instrumentation, although there are some requirements that are applicable to all types of devices. These requirements refer to the input circuits and accuracy.

Regarding input circuits, the power absorption shall not exceed 3 VA. The voltage input circuit of the measuring instrument shall be adapted to the nominal voltage and frequency of the supply voltage to be analysed and shall keep its characteristics and accuracy unchanged up to 1.2 times of its nominal voltage. It is suggested that stressing the input for $1 \mathrm{~s}$ by an a.c. voltage of four times the voltage setting or $1 \mathrm{kV}_{\text {rms }}$ whichever is less, should not lead to any damage in the instrument. The current input circuit should be adapted to the currents to be analysed. Each measuring input circuit should withstand a continuous stress of $1.2 \mathrm{I}_{\mathrm{N}}$ and a stress of $10 \mathrm{I}_{\mathrm{N}}$ for a period of $1 \mathrm{~s}$.

TABLE IV - Maximum measurement errors

\begin{tabular}{|c|c|c|c|}
\hline Class & Measurement & Conditions & $\begin{array}{c}\text { Maximum } \\
\text { allowable error }\end{array}$ \\
\hline \multirow{2}{*}{ A } & Voltage & $\begin{array}{l}\mathrm{U}_{\mathrm{m}} \geq 1 \% \mathrm{U}_{\mathrm{N}} \\
\mathrm{U}_{\mathrm{m}}<1 \% \mathrm{U}_{\mathrm{N}}\end{array}$ & $\begin{array}{c}5 \% \mathrm{U}_{\mathrm{m}} \\
0.05 \% \mathrm{U}_{\mathrm{N}} \\
\end{array}$ \\
\hline & Current & $\begin{array}{l}\mathrm{I}_{\mathrm{m}} \geq 3 \% \mathrm{I}_{\mathrm{N}} \\
\mathrm{I}_{\mathrm{m}}<3 \% \mathrm{I}_{\mathrm{N}}\end{array}$ & $\begin{array}{c}5 \% \mathrm{I}_{\mathrm{m}} \\
0.15 \% \mathrm{I}_{\mathrm{N}}\end{array}$ \\
\hline \multirow{2}{*}{ B } & Voltage & $\begin{array}{l}\mathrm{U}_{\mathrm{m}} \geq 3 \% \mathrm{U}_{\mathrm{N}} \\
\mathrm{U}_{\mathrm{m}}<3 \% \mathrm{U}_{\mathrm{N}}\end{array}$ & $\begin{array}{c}5 \% \mathrm{U}_{\mathrm{m}} \\
0.15 \% \mathrm{U}_{\mathrm{N}}\end{array}$ \\
\hline & Current & $\begin{array}{l}\mathrm{I}_{\mathrm{m}} \geq 10 \% \mathrm{I}_{\mathrm{N}} \\
\mathrm{I}_{\mathrm{m}}<10 \% \mathrm{I}_{\mathrm{N}}\end{array}$ & $\begin{array}{c}5 \% \mathrm{I}_{\mathrm{m}} \\
0.5 \% \mathrm{I}_{\mathrm{N}}\end{array}$ \\
\hline
\end{tabular}

With regard to accuracy, two classes of instrumentation are considered (A or B). Type A instruments are more accurate and are used for emission tests according to IEC 555-2. Table IV defines accuracy levels applied to the accuracy classes of instrumentation. $U_{m}$ and $I_{m}$ are the measured values corresponding to the $f_{m}$ frequency value. $\mathrm{U}_{\mathrm{N}}$ and $\mathrm{I}_{\mathrm{N}}$ are the nominal input ranges of the instrument. 
In the case of time-domain instrumentation the guide defines two approaches for the measurement of current and voltage harmonics. One is based on Fourier Transform and the other on digital filters.

From these two methods Fourier Transform is more commonly used in measuring instruments. The required characteristics depending on the harmonic type are summarized in Table V.

In addition, this guide stresses the importance of measuring other quantities apart from the voltage and current harmonics. Theses quantities are: phase-shifts between current and voltage harmonics of all considered orders, harmonic distortion, symmetrical components and interharmonics. Some of these indices can provide information about the presence of faults or abnormalities in the network.

TABLE V - Basic requirements for FFT based instrumentation

\begin{tabular}{|c|c|c|}
\hline $\begin{array}{c}\text { Category of } \\
\text { harmonics }\end{array}$ & $\begin{array}{c}\text { Recommended } \\
\text { window width }\end{array}$ & $\begin{array}{c}\text { Additional } \\
\text { requirements }\end{array}$ \\
\hline Quasi-stationary & $\mathrm{T}_{\mathrm{W}}=0.1-0.5 \mathrm{~s}$ & $\begin{array}{c}\text { Gaps between } \\
\text { windows may exist }\end{array}$ \\
\hline \multirow{2}{*}{$\begin{array}{c}\text { Fluctuating } \\
\text { (IEC 555-2) }\end{array}$} & $\begin{array}{c}\mathrm{T}_{\mathrm{W}}=0.32 \mathrm{~s} \\
\text { (rectangular) }\end{array}$ & No gap \\
\cline { 2 - 3 } & $\begin{array}{c}\mathrm{T}_{\mathrm{W}}=0.4-0.5 \mathrm{~s} \\
\text { (Hanning) }\end{array}$ & $\begin{array}{c}\text { Overlapping } \\
\text { half by half }\end{array}$ \\
\hline Quickly changing & $\begin{array}{c}\mathrm{T}_{\mathrm{W}}=0.08-0.16 \mathrm{~s} \\
\text { (rectangular) }\end{array}$ & No gap \\
\hline
\end{tabular}

\section{IEEE 519}

The standard IEEE 519 [4] provides guidelines and limitations for harmonic distortion from two perspectives: limitation of harmonic current distortion injected to the system by a customer, on one hand, and limitation of the harmonic voltage distortion supplied by the utility to the customer, on the other. Specifically, it recommends to maintain total voltage harmonic distortion below $5 \%$, and establishes a current distortion range of $2.5 \%$ to $20 \%$ at the Points of Common Coupling (PCC - the interface between sources and loads), as a function of voltage system and load size. Table VI summarises recommended voltage distortion limits.

TABLE VI - Voltage distortion limits

\begin{tabular}{|c|c|c|}
\hline $\begin{array}{c}\text { Bus Voltage } \\
\text { at PCC }\end{array}$ & $\begin{array}{c}\text { Individual Voltage } \\
\text { Distortion (\%) }\end{array}$ & $\begin{array}{c}\text { Total Voltage } \\
\text { Distortion } \\
\text { THD (\%) }\end{array}$ \\
\hline $69 \mathrm{kV}$ and below & 3.0 & 5.0 \\
\hline $69 \mathrm{kV}$ through $161 \mathrm{kV}$ & 1.5 & 2.5 \\
\hline $161 \mathrm{kV}$ and above & 1.0 & 1.5 \\
\hline
\end{tabular}

The IEEE 519 also gives some guidelines with regard to the effects of harmonics on protective relays and harmonic measurements.

\section{Influence of Power Quality on Protection Relays}

The influence of distorted waveforms on protective relays is not well documented because of the large variety of measuring principles employed in different relays. For example: electromechanical relays tend to respond to the fundamental frequency component of the distorted waveform. However, this may vary considerably among different manufacturers and electromechanical relay designs. Initially, static relays were overly sensitive to high frequency components but continuous model design revisions corrected these deficiencies. With the advent of microprocessor based numerical relays, filtering techniques were developed to accommodate a wide variety of phenomena. When we analyse the influence of wave quality on the performance of digital relays, it is necessary to distinguish two types of influences:

\section{A. Correct trips}

It is important to bear in mind that not all power quality related events leading to protection system operation are erroneous. Some protection relays by their design are destined to operate under certain anomalous conditions involving poor quality of power. An example of such operation is an undervoltage relay which can initiate a tripping sequence during voltage sags or short interruptions. Long voltage imbalances can also make protection units trip. In such cases, although tripping is caused or influenced by power quality related phenomenon, it is still a legitimate protection system operation.

In summary, it can be said that this type of distortion affects the relay performance, but does not cause incorrect operation.

\section{B. Incorrect trips}

On the other hand, some power quality related phenomena cause incorrect protection system operations. This is because the poor power quality conditions cause the relay to register erroneous input values, and for that reason, it acts erroneously. The opposite situation is also possible when the relay does not trip when it should, due to the poor power quality.

There are two phenomena that can make a relay work incorrectly. These are the variations in power frequency and the harmonic distortion.

\section{a) Power frequency variations}

In the case of power frequency variations, the relay magnitude measurement is based on input signal sampling. The input module takes a predefined number of samples in each cycle of fundamental frequency (typically from 8 at 64). From these samples, the RMS value of the signal is obtained [5]. 
In the case of 12 samples per cycle, sampling period is equal to $T_{i}=20 \mathrm{~ms} / 12=1.66 \mathrm{~ms}$. If an increase of frequency takes place but the sampling period is fixed (1.66 $\mathrm{ms}$ in this case) the resulting RMS value will be erroneous. The error appears in this case due to the fact that the RMS value calculated on the basis of 12 samples takes into account more than one cycle of the waveform (Fig. 2). Therefore, the calculated RMS value is erroneous.

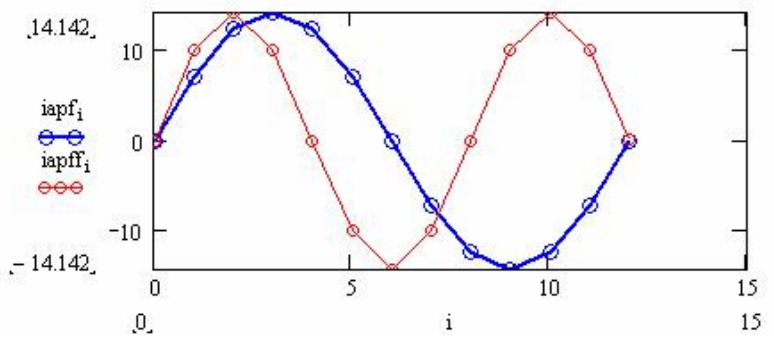

Fig. 2. Case of the system frequency increase and sampling frequency of 12 samples per $20 \mathrm{~ms}$ cycle

On the other hand, a decrease of frequency would cause an opposite effect. When using a fixed length measuring window of $20 \mathrm{~ms}$, the RMS value is calculated from a wave fragment shorter than a cycle (Fig. 3.), which also causes errors in the measure.

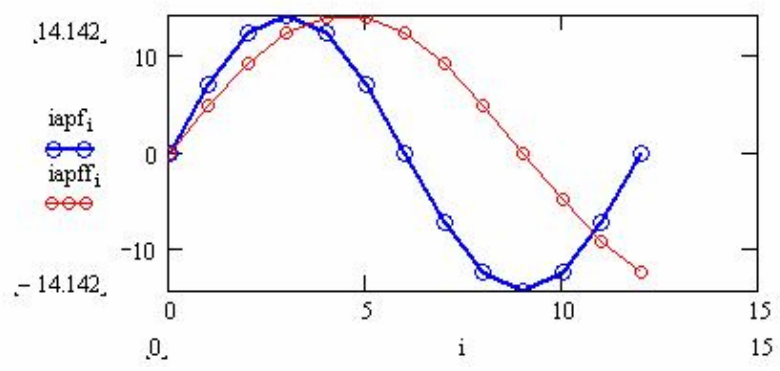

Fig. 3. Case of the system frequency decrease and sampling frequency of 12 samples per $20 \mathrm{~ms}$ cycle

To avoid this type of error, the digital relays must adapt the sampling frequency to the actual fundamental frequency in the system. On this way, we can be sure that the calculated RMS value is correct. Thus, in order to achieve correct measurement the relay needs to estimate power system frequency and adjust its sampling rate accordingly.

\section{b) Harmonic distortion}

The other phenomenon that can make a relay work incorrectly is harmonic distortion. Depending on the characteristics of the measured signal, in practice four types of harmonics can be found: quasistationary harmonics; fluctuating harmonics; rapidly changing harmonics, interharmonics as well as other spurious components. For protection relays rapidly changing harmonics have the worst effect. For this type of harmonics, it is recommended to make a continuous measure of the signal to detect any possible distortion.

High levels of harmonic in extreme cases can cause relay maloperation which is mainly a consequence of measurement error of the peak value and/or the angle of the waveform. For that reason, when measuring currents and voltages, the relays should measure the fundamental component of the signal alone. The standard IEC 1000-4-7 recommends using the Fourier Transform algorithm to filter out the harmonic distortion and to obtain the RMS value of the fundamental frequency signal only.

Another method utilised to obtain the RMS value is based on the calculations of the Mean Square value directly from the wave. This method does not eliminate the harmonics, and therefore, the calculated RMS value is different from that of the fundamental component alone. Higher RMS values are normally obtained with this method, which indicates that superfluous tripping activity can be produced by the relay in some cases.

Additionally, there are some other cases in which the presence of harmonic distortion can be interesting from the protection relay point of view. One such example is the case of differential protection of a transformer.

\section{Results}

In order to demonstrate these phenomena, several examples have been analysed by simulation, using the software tool Mathcad.

For the purposes of the impact of frequency variation, the behaviour of a distance digital relay subjected to a singlephase fault is analysed. Different wave frequencies are considered while the digital relay maintains constant sampling frequency of $1.66 \mathrm{~ms}$ (i.e. 12 samples per $20 \mathrm{~ms}$ cycle).

In order to illustrate harmonic distortion, an incorrect operation of a distance digital relay is presented. The relay calculates the RMS value with the Mean Square method instead with the Fourier Transform, and as a result, the relay produces an incorrect trip.

\section{A. Frequency variation}

The issue is to compare the response of a distance digital relay under single-phase fault conditions, for two different values of power system frequency $(50 \mathrm{~Hz}$ and $40 \mathrm{~Hz}$ ). It is assumed that the sampling period is fixed at $1.66 \mathrm{~ms}$ (12 samples per cycle at $50 \mathrm{~Hz}$ ). Current and voltage magnitudes during single-phase fault with power system frequency of $50 \mathrm{~Hz}$ are plotted in figures 4 and 5 .

Figures 6 and 7 show the same fault situation with a power system frequency of $40 \mathrm{~Hz}$. 


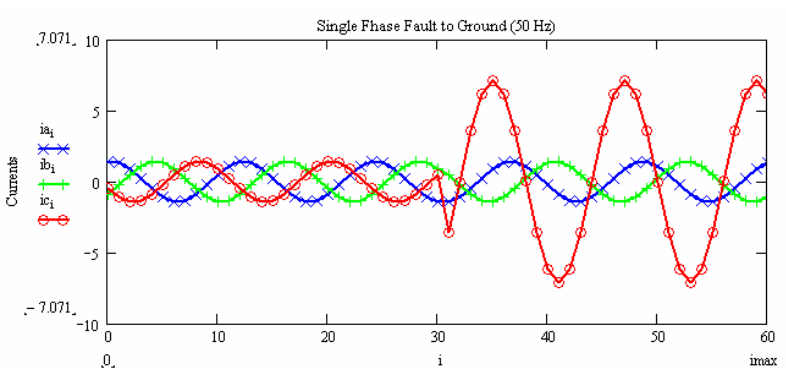

Fig. 4. Current waveforms during single-phase fault $(50 \mathrm{~Hz})$

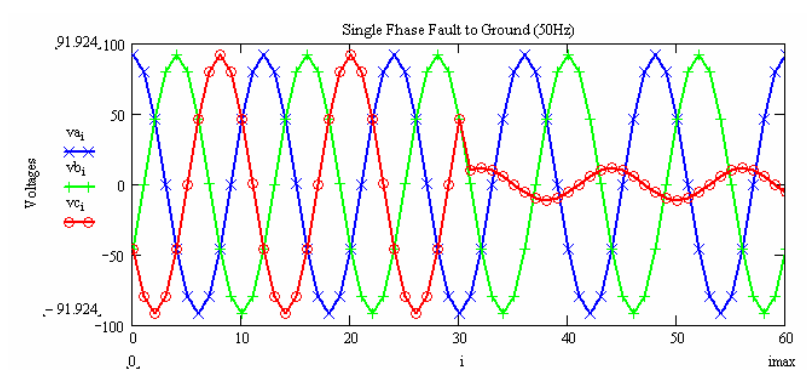

Fig. 5. Voltage waveforms during single-phase fault $(50 \mathrm{~Hz})$

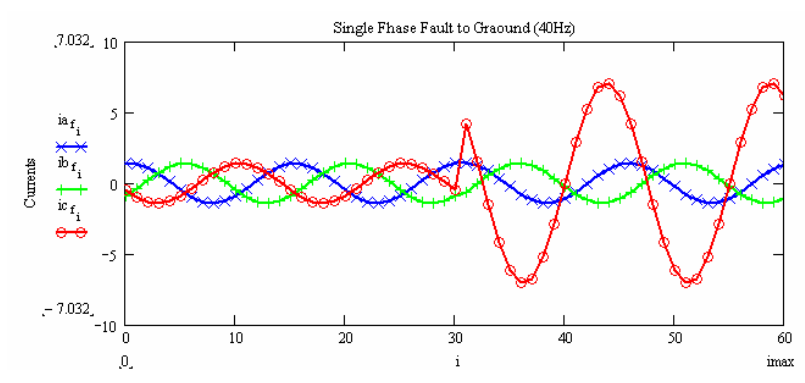

Fig. 6. Current waveforms during single-phase fault $(40 \mathrm{~Hz})$

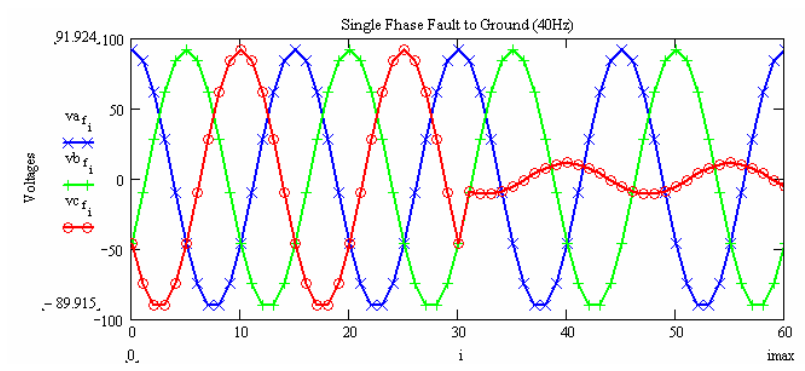

Fig. 7. Voltage waveforms during single-phase fault $(40 \mathrm{~Hz})$

Correctly evaluated magnitudes for the system frequency of $50 \mathrm{~Hz}$ are presented in figures 8 and 9. On the other hand at the frequency of $40 \mathrm{~Hz}$, if the samples are still taken every $1.66 \mathrm{~ms}$ (assuming 12 samples in each $20 \mathrm{~ms}$ period), only a fragment of the actual wave cycle will be taken into account. In this case a complete period would be obtained with 15 samples. Therefore, the calculated RMS value is erroneous, resulting in magnitude fluctuations as shown in figures 10 and 11.

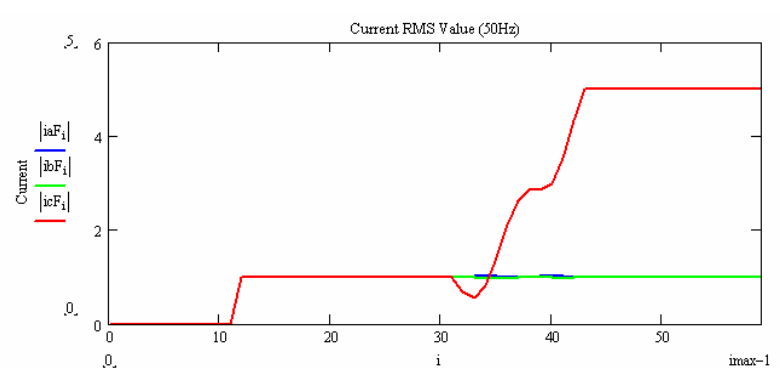

Fig. 8. Currents RMS value (50 Hz)

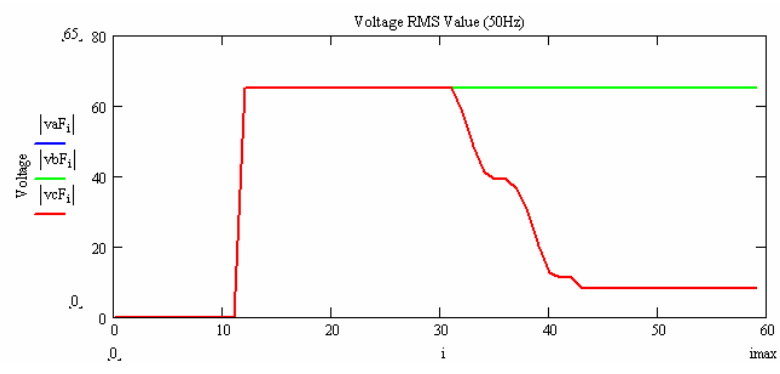

Fig. 9. Voltages RMS value $(50 \mathrm{~Hz})$

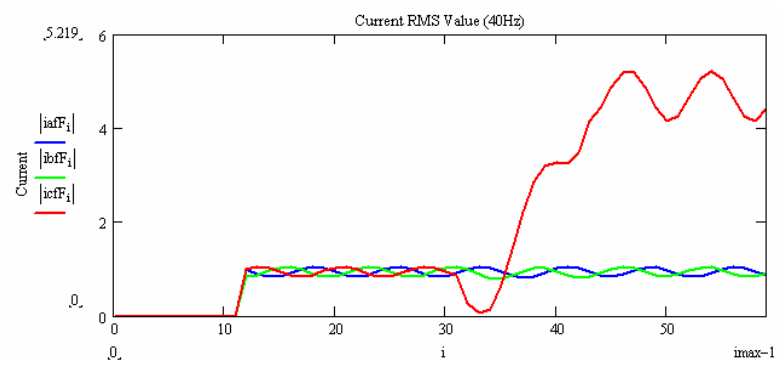

Fig. 10. Currents RMS value $(40 \mathrm{~Hz})$

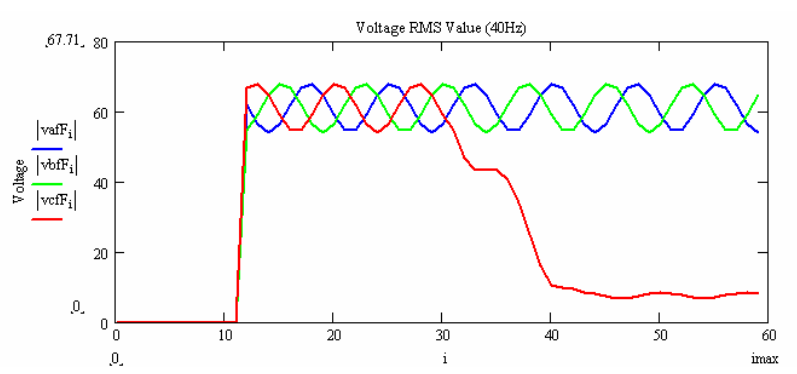

Fig. 11. Voltages RMS value $(40 \mathrm{~Hz})$

These oscillations of current and voltage magnitude can result in further measuring error accumulation in distance digital relays since the algorithm evaluates impedance value using a combination of both magnitudes. In consequence, the digital relay can act incorrectly, seeing a zone 2 fault as if it was located within zone 1 resulting in maloperation. The impedance locus as seen by the relay is presented in figures 12 and 13. The impedance trace moves through the protection zones which are defined by circles. The smallest circle represents instantaneously tripping zone 1 . 


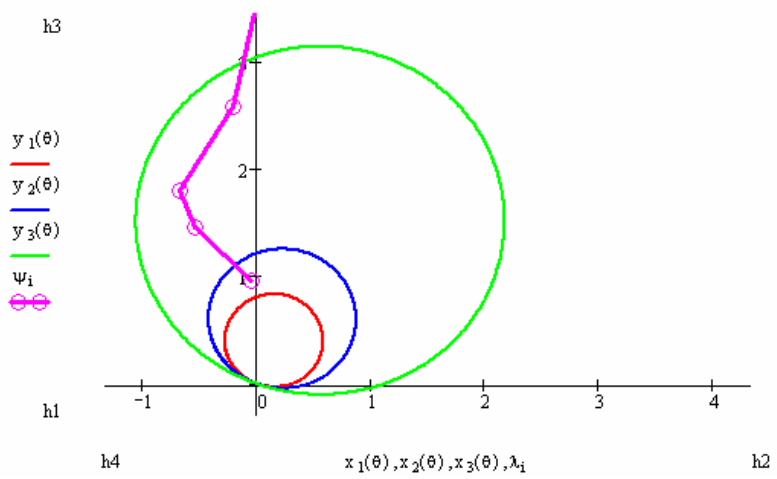

Fig. 12. Digital Relay Impedance Evolution $(50 \mathrm{~Hz})$

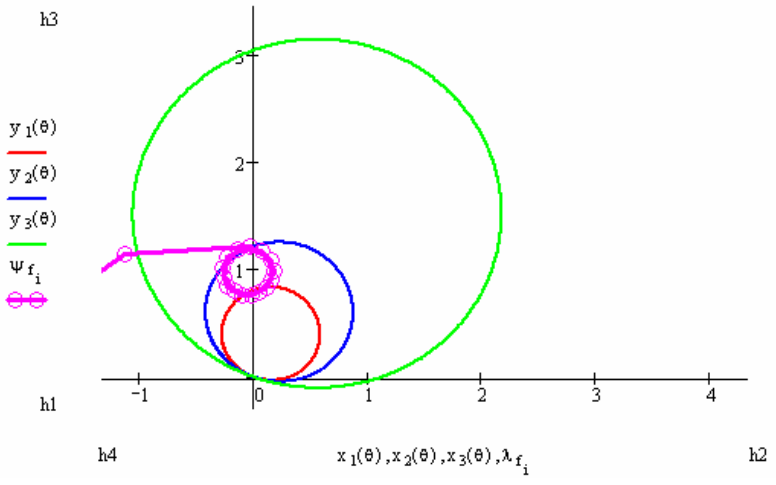

Fig. 13. Digital Relay Impedance Evolution $(40 \mathrm{~Hz})$

Finally, figures 14 and 15 show the response of the digital relay with power system frequencies of $48 \mathrm{~Hz}$ and $52 \mathrm{~Hz}$. It can be observed that the relay acts correctly when the frequency remains inside the range of frequencies recommended by the Standard EN 50160.

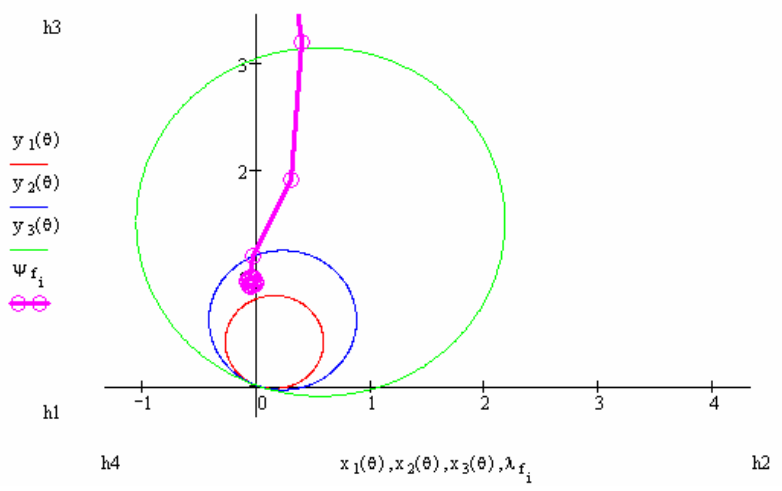

Fig. 14. Digital Relay Impedance Evolution (48 Hz)

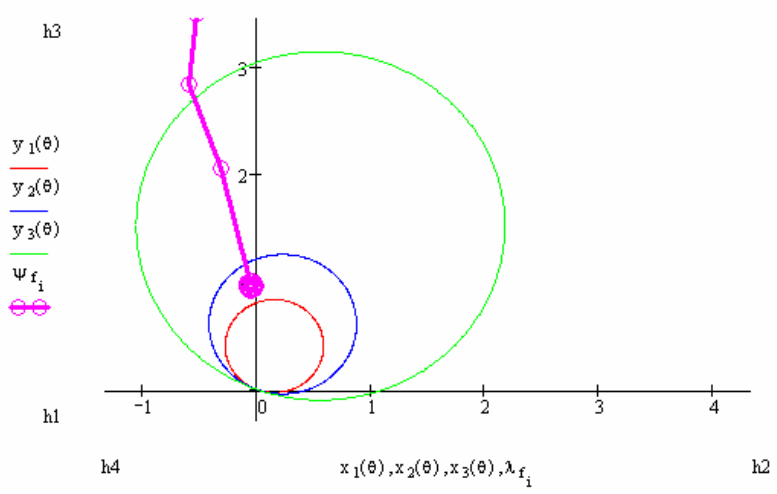

Fig. 15. Digital Relay Impedance Evolution (52 Hz)

\section{B. Harmonic distortion}

This case study presents a single-phase to earth fault on a transmission line with high harmonic content. It is assumed that the only existing harmonics are the $5^{\text {th }}$ and the $7^{\text {th }}$. The distance digital relay calculates the voltage and current RMS values from the distorted input waveforms (Figures 16 and 17).

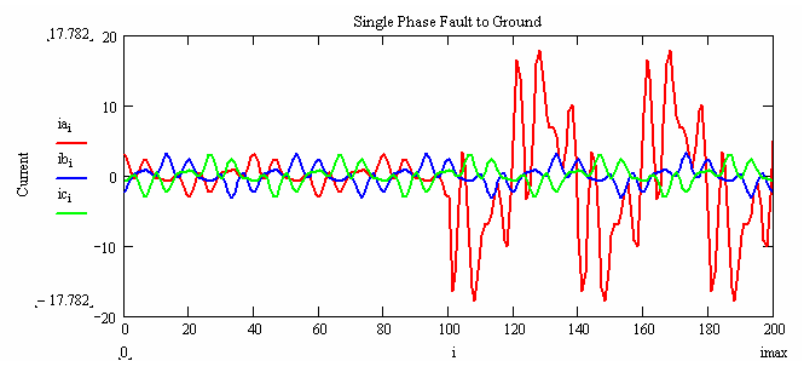

Fig. 16. Current waveforms during single-phase fault

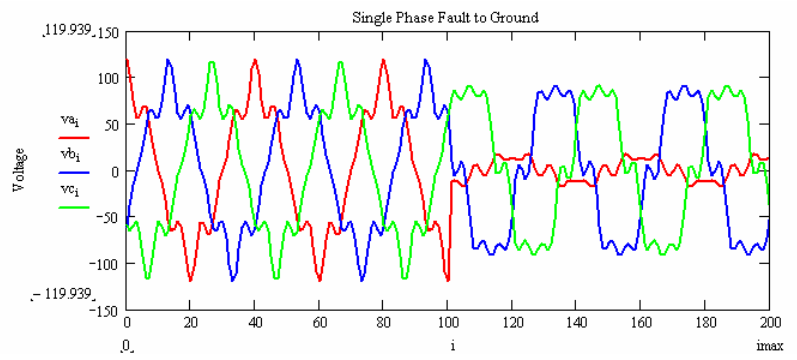

Fig. 17. Voltage waveforms during single-phase fault

Figures 18 and 19 illustrate the difference between two RMS calculating methods, one based on the Mean Square value and the other on Fourier Transform. In this specific case, due to the presence of harmonics, the values obtained through the Mean Square value method is higher than the value obtained through the Fourier Transform. This is due to the fact that the Fourier Transform based method filters out higher harmonics and the final result contains fundamental frequency component only.

Once this RMS value is obtained, impedance evaluating algorithms of the digital relay are applied. The final response of the digital relay is presented in figures 20 and 21.

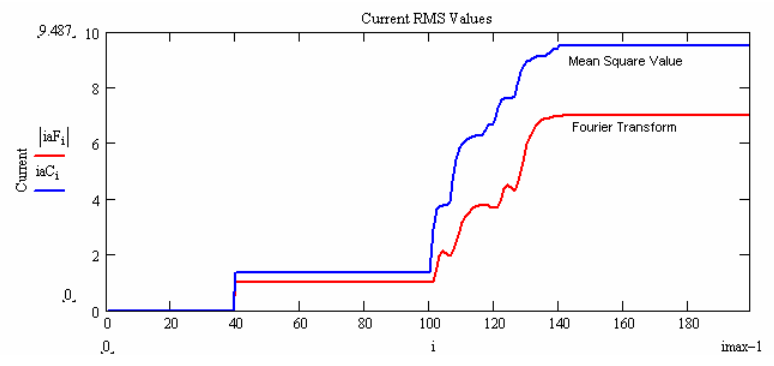

Fig. 18. Current RMS value. 


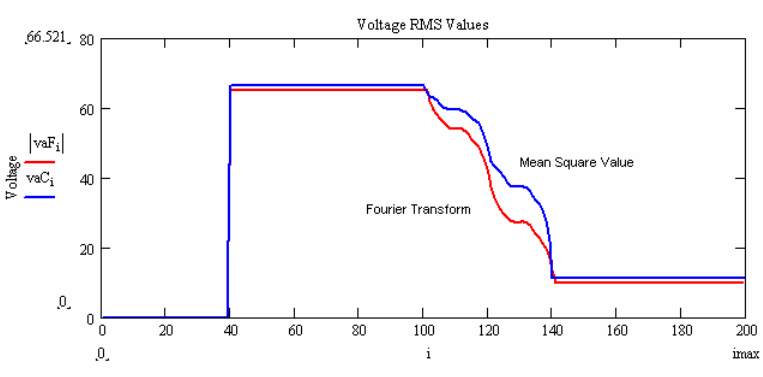

Fig. 19. Voltage RMS value

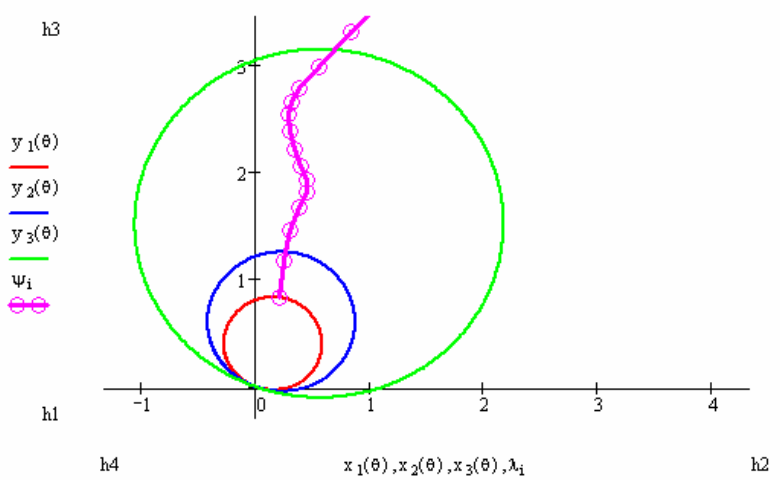

Fig. 20. Digital Relay Impedance Evolution for Fourier Transform based algorithm.

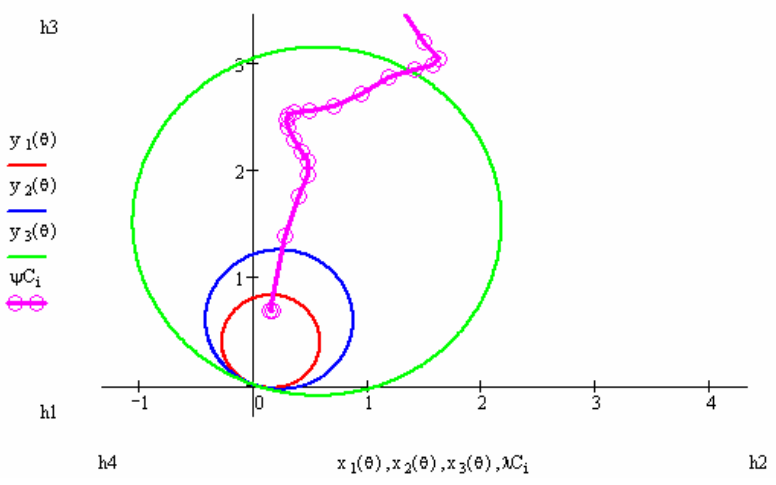

Fig. 21. Digital Relay Impedance Evolution for Mean Square Value based algorithm

It can be observed how a fault located in zone 2 of protection (figure 20), is seen in zone 1 by a digital relay which uses Mean Square method to obtain the RMS value. This digital relay will give an incorrect trip (figure 21).

\section{Conclusions}

This paper analyses different power quality phenomena and their influence on digital protection relays. Digital relays are the last generation relays. Based on microprocessor and software, these devices are applied mainly in transmission system and generator unit protection but their applications grow rapidly with the advancements in microprocessor and communication industries.

The last part of the paper analyses how two phenomena such as frequency variation and harmonic distortion influence digital protection relays. In the first case, the solution is to adapt relay sampling frequency to the actual power system frequency. In the case of harmonic distortion, the Fourier Transform filters harmonics, and therefore it is recommended to use it to calculate the RMS value.

\section{References}

[1] Fan Wang, "Power Quality Disturbances and Protective Relays" (PhD). Chalmers University of Technology, Sweden. March 2001.

[2] EN 50160-1999: "Voltage characteristics of electricity supplied by public distribution system".

[3] IEC 1000-4-7: "General guide on harmonics and interharmonics measurements and instrumentation, for power supply systems and equipment connected".

[4] IEEE Std 519-1992: "IEEE Recommended Practices and Requirements for Harmonic Control in Electrical Power Systems".

[5] IEEE WG C-2. "Protective relaying and power quality", Draft 4, June 2003.

[6] Lee, T. M.; Chan, T. W., "An investigation on the effects of harmonic contents and phase shift on the performance of RCCB and over-current relays", Proceedings of the International Power Engineering Conference (IPEC' 97), Vol. 2, 1997, Page(s): 775-779.

[7] Stringer, N. T., "The effect of DC offset on currentoperated relays", IEEE Transactions on Industry Applications, Vol. 34 1, Jan.-Feb. 1998, Page(s): 30 -34.

[8] D. G. Hart, W. Peterson, D. Uy, J. Schneider, D. Novosel, R. Wright, "Tapping Protective Relays for Power Quality Information", IEEE Computer Applications in Power, January 2000. 